\title{
Zur Redaktion des Psalters.
}

Dass die Einteilung des Psalters in fünf Bücher nach Analogie der Thoraeinteilung erfolgt ist, wussten schon die griechischen Exegeten. Dunkler ist das Princip, welchem die Einteilung im Einzelnen folgte. Der Abschnitt hinter dem 72. Psalm war durch die Unterschrift: „Zu Ende sind die Gebete Davids" gegeben; derselbe Grund lag bei der Teilung hinter dem 42. Psalm. vor, und dass vor dem 90. Psalm ein Absatz gemacht wurde, ist gleichfalls erklärlich. Warum aber schliesst das vierte Buch mit dem 106. Psalm?

Leicht begreiflich wäre das bei der Annahme Hitzig's (die Psalmen, II. I865, p. IX. X), dass die beiden letzten Verse des Psalms aus der Chronik, I. I6, 35. 36, entnommen seien. Hinterher konnte dann, wie Hitzig bemerkt, ein Diasceuast. den letzten Vers als Merkstein sich gefallen lassen. Dieselbe Ansicht vertritt auch Jacob (in dieser Zeitschrift, XVI. I50 ff.): danach spricht das Volk die Doxologie I Chr. 16, 34; .David spricht zum Schlusse v. 35.36 und das Volk antwortet darauf. „Deshalb glauben wir auch, dass die beiden Verse Ps. 106, 47. 48. aus der Chronik entnommen oder doch nach ihr redigiert sind" (1. c. p. 152 ).

Allein das ist unmöglich. Dass diese Verse aus dem Psalter übernommen sind, ist schon daraus zu folgern, dass die in der Chronik vorhergehenden Psalmtöne wirkliche 
Citate aus dem Psalter sind, wie schon ein oberflächlicher Vergleich zeigt und auch alle Exegeten mit alleiniger Ausnahme Hitzigs anerkennen. Und wie konnte der Chronist seinem Helden David die Bitte in den Mund legen: „Und sammle uns und rette uns vor den Heiden!" wenn er dies Gebet selbständig verfasste?

Sind also diese Verse in Psalter ursprünglich, so gehört zunächst das im masorethischen Texte am Ende des 106. Psalms stehende הלוזיה an den Anfang von Ps. 107. Das beweist I) $\mathfrak{6}$; denn mit Unrecht behauptet Baethgen in der ersten Auflage seines Kommentars, das Hallelujah fehle in $\mathfrak{G}$; es steht nur am Anfange von Ps. IO7. Das beweist 2) das Fehlen des Halleluja in den Doxologien am Schlusse der vorhergehenden Psalmbücher, 41, 14. 72, I9 und 89, 53; dass es am Schlusse des Ps. I 50 steht, kommt hier nicht in Betracht. Dafür spricht 3) die Analogie von Ps. 106 und I05 65. ${ }^{x}$ Das Halleluja am Schlusse von Ps. I05 erklärt sich aus Dittographie oder späterer Gleichmacherei, würde auch in unserem Falle nichts beweisen, weil dann das Halleluja zum Psalme selbst, also zu v. 46 gehörte, nicht aber zur. Doxologie. - Somit haben wir in Ps. I05, I06 und I07 ein zusammengehöriges Ganze vor uns, eine Trilogie, welche in drei je durch ein neues Halleluja bezeichneten Absätzen die ganze Geschichte Israels dichterisch behandelt, wie das Delitzsch richtig ausführt (die Psalmen 4, 1883, p. 707).

In den ganzen Zusammenhang dieser drei Psalmen passt nun aber der Vers 106, 47: „Verleih uns Sieg, Jahve, und sammle uns aus den Heiden!" nicht hinein; denn der in

I Dass das הללו-יה am Ende von Ps. Io4 ebenfalls an den Anfang von Ps. 105 gehört, wo es G hat, beweist Ps. I03. Beide Psalmen, I03 und 104, beginnen und schliessen mit ברכי נפשי אתייהוה; cf. XVI, 159. 
I07, 2 sich fortsetzende-historische Bericht schliesst an 106, 46 an. 106, 47 gehört also ebenso wie der folgende Vers zur redaktionellen Schlussformel. Schon Hitzig bemerkte (1. c. pag. X), dass v. 47 und 48 zusammengehören, nur zog er andere Consequenzen daraus. Vers 47 ist eine an 46 anknüpfende liturgische Formel, wie wir ähnliche am Schlusse anderer Pericopen des A. T. finden.

Schloss nun Ps. 106 ursprünglich mit v. $46 \mathrm{ab}$, so kann bei der, dann um so deutlicheren, engen Verbindung der Ps. 105-107 den Redaktor, der den Psalter durch die bekannten Schlussformeln in 5 Bücher teilte, ein.innerer, sachlicher Grund, wie in den andern Fällen, nicht bewogen haben, hinter Ps. I06 zu teilen. Nur ein äusserer Grund kann vorgelegen haben, und dieser kann nur der gewesen sein, dass in der Handschrift die Mitte zwischen Ps. 90 und dem Schlusse des Psalters mit dem Ende von Ps. I06 zusammenfiel. Da nun in unserem Psalter das 5. Buch an Umfang doppelt so gross ist wie das vierte, so kann der Redaktor nicht unser ganzes 5. Buch gekannt haben.

Dafür spricht ein zweiter Umstand. Wir dürfen annehmen, dass der Redaktor, der das Explicit jedes einzelnen Psalmbuches durch die Doxologie: 'ברוך יהוֹה וגו markierte, durch dieselbe, vielleicht nur ausführlichere, Formel auch den Schluss des ganzen Psalters bezeichnete. : Dieser Erwartung entspricht Ps. I50 nicht; dagegen zeigt die Conברוך cordanz, dass das für das Buchende charakteristische וג im fünften Buche am Schlusse eines Psalms nur I35, 2 I vorkommt. Der Psalter unseres Redaktors schloss also mit Ps. I 35 ab.

Dieser Psalm entspricht durchaus allen Bedingungen eines Schlusspsalms. Nachdem die Gruppe der Stufenlieder abgeschlossen ist, fasst er den ganzen Inhalt des Psalters in ein festliches Preis- und Danklied zusammen und läuft 
schliesslich in eine vierstimmige Berakha aus: Ganz Israel, ihr Priester, ihr Leviten und ihr Proselyten, ברכו אתייהוה!, worauf dann das charakteristische ברוך יהוה וגו' folgt. Gerade dass diese Schlussdoxologie weit ausführlicher ist als die der vorhergehenden Bücher, ist bezeichnend; cf. Ps. 150.

Freilich steht auch jetzt Ps. 106 noch nicht genau in der Mitte, denn Ps. 90-106 zählen 323, Ps. 107-135 dagegen 478 Verse. Allein in dies letzte Buch gehört Ps. II9 nicht hinein; er passt weder zu den vorhergehenden Lobpsalmen, noch zu den folgenden Stufenpsalmen. Zieht man also seine 176 Verse ab, so bleiben 322 Verse, eine Zahl, die mit der Verszahl des vierten Buches fast genau stimmt. $\mathrm{Da}$ der Psalter ursprünglich stichisch geschrieben ist, so wird, wenn die Zahl der Verse übereinstimmt, auch die der Stichen übereingestimmt haben.

Ps. 136 bildet nicht mit den vorhergehenden eine Gruppe, wie schon seine äussere Form zeigt, sondern ist das Einleitungslied eines Nachtrags zum Psalter, der durchsichtig geordnet ist: zwei Eingangslieder wie im ersten Buche; dann ein Nachtrag davidischer Psalmen I38-I45 und endlich 5 Hallelpsalmen. .Erst durch diesen Nachtrag hat das fünfte Buch einen grösseren Umfang als alle vorhergehenden erhalten, was gewiss nicht ursprünglich ist.

LIC. TH. W. RIEDEL. 